\title{
Infection Rate Related to Permanent Hemodialysis Catheters
}

\author{
Hatem Hussein*, Sheriff Reffat, Mohammad El Yamany, Tarek Farouk, \\ Mamdouh AL-Mezaien
}

Department of Surgery, Faculty of Medicine, Suez Canal University, Egypt

\begin{abstract}
Background: Centrally placed venous catheters for hemodialysis have become an essential part of recently established medical care given to end stage renal disease (ESRD) patients. Dialysis access related blood stream infection and the complications related to such problem requiring hospitalization, account for almost $1 / 3$ of the cost of ESRD management, with documented death rate of $12-25.9 \%$. Aim: The present study aimed to assess infection rate related to permanent hemodialysis catheters performed at Suez Canal University Hospital. Patients and Methods: thirty-five patients were included in this study. All of them had an interventional session to place a tunneled cuffed hemodialysis catheter for ESRD. Evaluation of the procedure and its outcome was done. Results: No blood stream catheter-related infection occurred in $45.7 \%$ of the study population. Only 2 patients (5.7\%) had infection within the first week, 1 patient (2.9\%) infection was within the first month and in the remaining 16 patients had their first blood stream catheter-related infection episode after the first month. Conclusion: Previous history of blood stream infection associated with a dialysis catheter increases the probability of infection to the newly inserted permanent catheter, before reaching 6 months' life time despite changing access site.
\end{abstract}

Key words: end stage renal disease, infection, Suez Canal

\section{Introduction}

Centrally placed venous catheters for hemodialysis have become an essential part of recently established medical care given to ESRD patients. The most important criteria that define centrally placed catheters is that their tips are positioned at the cavo-atrial area. Tunneled cuffed catheter is one of the devices used to be placed in a central vein for the purposes needing long term vascular access more than 3 weeks as determined by the national kidney foundation guidelines (NKF-DOQI)(1). Tunneled cuffed dialysis catheter has an important superiority over regular central venous catheters which is having a subcutaneous cuff which when placed subcutaneously it starts ingrowth forming a barrier that stops or delays infection ${ }^{(2)}$. Dialysis access related blood stream infection (BSI) and the complications related to such problem requiring hospitalization, account for almost $1 / 3$ of the cost of ESRD management with documented death rate of $12-25.9 \%(3)$. International reports stated that a 250,000 cases of central venous catheter associated BSI occurs annually that when analyzed found to cost too much in the terms of morbidity and financially, so preventive guide-lines had been established to prevent such infection through a multidisciplinary effort involving 
health care professionals who insert or remove CVCs, catheter maintenance provider, infection control personnel, and those who allocate resources ${ }^{(4)}$. The two most commonly used blood-compatible materials for hemodialysis catheters are silicone and polyurethane(5). Infection associated with hemodialysis catheters has emerged as the most prominent and most serious complication that is encountered, and is responsible for failure of $6 \%-28 \%$ of catheters $^{(6)}$. One should know that the real problem of catheter related infection is blood stream infection. This condition from the different catheter related infection presentations is the actual determent of catheter working life and the major problem all the preventive measures and placement guide-lines aim to control. The incidence of bacteremia related to tunneled cuffed catheters was described by Marr et al as being one event per 252 days ${ }^{(7)}$. The danger of CRBSI lies within the consequences which occur secondary to it. These consequences may have a grave results to the patient and may lead to death such as endocarditis, epidural abscess, and septic shock $(7,8)$. CRBSI may occur very early after catheter placement which suggests a cause related to the catheter placement event or may occur at a point in time distant from the time of insertion which suggests that the factors of pathogenesis are located within the hemodialysis facility and related to the nursing of the catheter ${ }^{(9)}$. Prevention of catheter related infection is the first and most important thing we should be oriented with and doing it while executing our protocols to place and maintain hemodialysis catheters. It should be a reflex attitude. That when one knows that an attack of BSI cost ranges from USD 3,700 to USD $29,000^{(3)}$, as well as the miserable state that the patient suffers then prevention of catheter infection should be given the value it deserves. When tunnel is in- fected proximal to the cuff the problem is serious as this area is close to the blood stream. When this event occurs most probably the culture result will be positive, thus it is actually a tunnel mediated CRBSI. The appropriate treatment consists of proper parenteral antibiotics according to culture and sensitivity and catheter removal. The catheter should not be replaced at this site $e^{(1,9)}$.

\section{Patients and Methods}

This prospective study was conducted over a period from May 2014 to January 2016. Thirty-five patients on chronic regular hemodialysis were included according to the following criteria were legible for the study: Has no vein for Arterio-venous fistula or graft. Had an AVF, and need the catheter till maturation of the fistula. Has persistent hypotension. Patients who had replaced a catheter in a new access site were considered a new case.

The procedure: Under cardiac monitoring, sufficient amount of local anesthesia was administered to completely anesthetize the insertion site including the subcutaneous tunnel area. Under ultrasound guidance, the selected vein was punctured using a seldinger needle attached to a syringe, when intra-luminal blood was aspirated, syringe was removed and a wire was passed under fluoroscopic guidance to ensure smooth passage with no kinks and to guard against right atrial entry as it may provoke arrhythmia. With the wire held securely the needle was removed leaving the guide-wire in the target vein and the cutaneous exit site of the wire was enlarged using a scalpel. A small incision was made at the planned exit site on the chest wall, approximately $8-10 \mathrm{~cm}$ below the clavicle for the IJ or SC veins or at the pelvic region for the femoral vein. This was widened using blunt dissection. After that, the catheter was attached to the trocar then the trocar was advanced 
through the opening of the exit sit toward the opening at the puncture site creating the subcutaneous tunnel. Catheter was led gently through the tunnel aiming to pull the tunneler straight not in angel to prevent damage to the catheter tip. Tunnel length was tailored to keep the Y-hub of the catheter from entering the exit site also to keep the cuff $2 \mathrm{~cm}$ minimum from the skin opening. Vein entry site was dilated using the provided dilator, and then the valvular sheath was introduced over the guide-wire to the lumen of the vein, after which the dilator and guide-wire were removed and the distal tip of the catheter was inserted through the sheath which was peeled-away. Under fluoroscopic guidance, catheter tip was placed at the junction of the superior vena cava with the right atrium. A syringe was attached to both extensions one at a time and clamps were opened, blood should aspirate easily from both sides if one side exhibited resistance to aspiration then the catheter was rotated or repositioned. Once adequate flow was achieved both lumens were irrigated with saline using quick bolus technique. To maintain patency a heparin lock was created in both lumens. Once locked with heparin clamps were closed, and caps were installed on the extensions. Catheter was sutured to the skin through its wings for all the period of implantation. Insertion site was covered with transparent dressing to enable easy visual inspection. A completion fluor- oscopic image was obtained to confirm that everything was going well. Patient discharged in the same day, seen after 3 days, and every month up to 12 months. Data regarding insertion success, obstruction and infection during use were documented. The study endpoints were: 1) Death of the patient.2) Catheter removal due to i) Obstructed flow, ii) Infection, iii) No longer needed. Or 3) Good functioning catheter for 12 months.

\section{Results}

This study included 35 patients. Males constituted $31.4 \%$ and females constituted 68.6\%. $22.9 \%$ were diabetics, $51.4 \%$ were hypertensive, and $5.7 \%$ had IHD, table (1). The most frequently used vein was the right internal jugular which was used in $45.7 \%$ of the patients, followed by the left internal jugular vein in $31.4 \%$ of the patients, and the left subclavian, right femoral and left femoral veins were used of equal percentage $(5.7 \%)$, least in frequency (only 1 patient) was the right subclavian vein, (figure 1).

Table 1: Study population characteristics

\begin{tabular}{|l|c|c|}
\hline & Frequency & $(\%)$ \\
\hline Male & 11 & 31.4 \\
\hline Female & 24 & 68.6 \\
\hline Age: Mean \pm SD & $59.17 \pm 12.508$ \\
\hline Diabetes & 8 & 22.9 \\
\hline Hypertension & 18 & 51.4 \\
\hline Ischemic Heart Dis & 2 & 5.7 \\
\hline
\end{tabular}

Figure 1: The vein in which the catheter was inserted among study population 
The mean of number of catheter days was $183 \pm 161$ days. It ranged from 0 to 730 days. The mean of primary device service interval was $127 \pm 102$ days. It ranged from 15 to 330 days, (table 2). Regarding the infection, it occurred in 19 patients (54.3\%). Only $5.7 \%$ occurred within the first week and the rest $48.6 \%$, occurred after that time, (table 3). Bu the end of the study, 23 catheters were removed for the different reasons shown in (table 4). All the quantitative variables had significant differences within the study population; $p$-value $<0.0001$ (table 5).

Table2: Descriptive data of some quantitative variables

\begin{tabular}{|l|c|c|c|}
\hline Variable & Mean \pm SD & Minimum & Maximum \\
\hline & & 24 & 80 \\
\hline Number of catheter days & $182.94 \pm 160.672$ & 0 & 730 \\
\hline Primary device service interval & $126.50 \pm 102.229$ & 15 & 330 \\
\hline
\end{tabular}

Table 3: Showing the times of onset of infection among study population

\begin{tabular}{|l|c|c|}
\hline & Frequency & Percentage (\%) \\
\hline No infection & 16 & 45.7 \\
\hline Infection within first week & 2 & 5.7 \\
\hline Infection 2 weeks -first month & 1 & 2.9 \\
\hline Infection after first month & 16 & 45.7 \\
\hline Working up to 6 months & 18 & 51.4 \\
\hline Working up to 1 year & 4 & 11.4 \\
\hline
\end{tabular}

Regarding the logistic regression of several variables that resulted in a non-significance of all the variables and the constant; even the odds ratio of some variables was more than one. Those variables with extremely large odds ratio indicate the probable co-linearity of both the variable under test and the infection occurrence variable. This indicates that none of the variables in the table of logistic regression are of non-significant effect upon the catheter-associated blood stream infection, (table 6). A perfect correlation between number of catheter days and primary device service interval was found i.e., primary device service interval increases significantly with the increase of number of catheter days (table 7).

Table 4: Reasons of inserted catheters removal among the study population

\begin{tabular}{|l|c|c|}
\hline & Frequency & Percentage (\%) \\
\hline Still working (remaining not removed) & 12 & 34.3 \\
\hline Died & 9 & 25.7 \\
\hline No longer required & 1 & 2.85 \\
\hline Not patent & 8 & 22.85 \\
\hline Potential associated BSI & 5 & 14.3 \\
\hline
\end{tabular}

Table 5: Significance within study population for quantitative variables

\begin{tabular}{|l|c|c|}
\hline & $t$ & p-value \\
\hline Age & 27.988 & $<0.0001^{*}$ \\
\hline Number of catheter days & 6.736 & $<0.0001^{*}$ \\
\hline Primary device service interval & 5.534 & $<0.0001^{*}$ \\
\hline
\end{tabular}


Table 6: Logistic regression

\begin{tabular}{|l|c|c|c|}
\hline & B & p-value & Odds ratio \\
\hline Age & -16.138 & 0.993 & 0 \\
\hline Gender & 130.467 & 0.998 & $4.58322 \mathrm{E}+56$ \\
\hline Diabetic & 361.016 & 0.993 & $6.1246 \mathrm{E}+156$ \\
\hline Hypertensive & -268.386 & 0.994 & 0 \\
\hline Cardiac & 85.151 & 1.000 & $9.56747 \mathrm{E}+36$ \\
\hline Pre-Failure Kidney Disease & -155.017 & 0.994 & 0 \\
\hline Previous CVC With History Of BSI & -178.459 & 0.995 & 0 \\
\hline Inserted By & -68.490 & 0.999 & 0 \\
\hline Number of Catheter Days & 1.046 & 0.993 & 2.847 \\
\hline Constant & 750.714 & 0.996 & \\
\hline
\end{tabular}

Table 7: Correlation for quantitative variables

\begin{tabular}{|l|c|c|c|c|c|c|}
\hline & \multicolumn{2}{|c|}{ Age } & \multicolumn{2}{c|}{$\begin{array}{c}\text { Number of catheter } \\
\text { days }\end{array}$} & \multicolumn{2}{c|}{$\begin{array}{c}\text { Primary device ser- } \\
\text { vice interval }\end{array}$} \\
\hline & $r$ & p-value & $r$ & p-value & $r$ & $p$-value \\
\hline Age & & & -0.065 & 0.712 & 0.304 & 0.193 \\
\hline Number of catheter days & -0.065 & 1.000 & & & $1.000^{*}$ & $<0.0001$ \\
\hline $\begin{array}{l}\text { Primary device service } \\
\text { interval }\end{array}$ & 0.304 & $<0.0001$ & $1.000^{*}$ & $<0.0001$ & & \\
\hline
\end{tabular}

*. Correlation is significant at the 0.01 level (2-tailed).

A significant strong positive correlation was found between fate of catheter/patient and reason of catheterremoval. While, a significant moderate positive correlation between: Catheter completion of 1 year in-site and prefailure kidney disease. Catheter completion of six months in-site and previous central venous catheterization with history of catheter-related blood stream infection. Intensive care unit admission due to catheter-related blood stream infection and previous central venous catheterization with history of catheterrelated blood stream infection. Person inserting catheter and catheter completion of 1 year in-site. vein used for insertion and death related to catheterrelated blood stream infection. Number of catheter days and catheter completion of 1 year in-site. Number of catheter days and reported events of catheter- related blood stream infection. Number of catheter days and time of onset of infection. Number of catheter days and catheter-inserting person. Catheter completion of 1 year in-site and catheterinserting person. Catheter completion of 6 months in-site and time of onset of infection. Primary device service interval and reported events of catheter-related blood stream infection. Primary device service interval and time of onset of infection. Reported events of catheterrelated blood stream infection and time of onset of infection. Time of onset of infection and catheter completion of 6 months in-site. A significant moderate negative correlation was found between: Date of insertion and catheter completion of 1 year in-site. Person inserting catheter and fate of catheter/patient. Person inserting catheter and reason for catheter removal. 
Table 8: Correlations between most of the variables of the study

\begin{tabular}{|c|c|c|c|c|c|c|c|c|}
\hline & 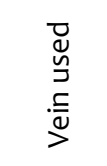 & 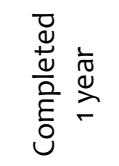 & 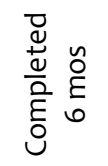 & 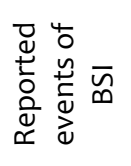 & 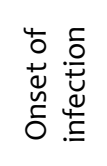 & $\underset{⿱ 亠 䒑}{\stackrel{ \pm}{\leftarrow}}$ & 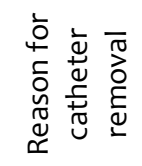 & 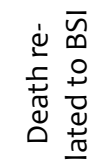 \\
\hline $\begin{array}{l}\text { Age } \\
\quad \mathrm{P} \\
\mathrm{p} \text {-value } \\
\end{array}$ & $\begin{array}{l}0.14 \\
0.40 \\
\end{array}$ & $\begin{array}{c}-0.27 \\
0.11 \\
\end{array}$ & $\begin{array}{l}0.03 \\
0.84\end{array}$ & $\begin{array}{l}-0.16 \\
0.35 \\
\end{array}$ & $\begin{array}{r}-0.07 \\
0.67 \\
\end{array}$ & $\begin{array}{l}0.11 \\
0.49 \\
\end{array}$ & $\begin{array}{c}-0.04 \\
0.78 \\
\end{array}$ & $\begin{array}{l}0.19 \\
0.26\end{array}$ \\
\hline $\begin{array}{l}\text { Gender } \\
\mathrm{P} \\
\mathrm{p} \text {-value }\end{array}$ & $\begin{array}{l}0.07 \\
0.65\end{array}$ & $\begin{array}{l}0.05 \\
0.77\end{array}$ & $\begin{array}{l}0.20 \\
0.24\end{array}$ & $\begin{array}{l}0.17 \\
0.31\end{array}$ & $\begin{array}{l}-0.03 \\
0.83\end{array}$ & $\begin{array}{c}-0.007 \\
0.97\end{array}$ & $\begin{array}{l}0.13 \\
0.44\end{array}$ & $\begin{array}{c}-0.09 \\
0.57\end{array}$ \\
\hline $\begin{array}{c}\text { Diabetics } \\
\quad \mathrm{P} \\
\mathrm{p} \text {-value }\end{array}$ & $\begin{array}{l}0.08 \\
0.63\end{array}$ & $\begin{array}{l}-0.06 \\
0.70\end{array}$ & $\begin{array}{l}-0.02 \\
0.89 \\
\end{array}$ & $\begin{array}{l}0.16 \\
0.35\end{array}$ & $\begin{array}{l}0.04 \\
0.81 \\
\end{array}$ & $\begin{array}{c}-0.06 \\
0.71\end{array}$ & $\begin{array}{c}-0.06 \\
0.69 \\
\end{array}$ & $\begin{array}{l}0.20 \\
0.22\end{array}$ \\
\hline $\begin{array}{l}\text { Hypertensive } \\
\text { patient } \\
\text { P } \\
\text { p-value }\end{array}$ & $\begin{array}{l}0.09 \\
0.59\end{array}$ & $\begin{array}{l}-0.09 \\
0.59\end{array}$ & $\begin{array}{l}0.04 \\
0.80\end{array}$ & $\begin{array}{l}0.01 \\
0.92\end{array}$ & $\begin{array}{l}-0.05 \\
0.74\end{array}$ & $\begin{array}{l}0.09 \\
0.57\end{array}$ & $\begin{array}{c}-0.09 \\
0.59\end{array}$ & $\begin{array}{l}-0.14 \\
0.40\end{array}$ \\
\hline $\begin{array}{l}\text { Cardiac patient } \\
\text { P } \\
\text { p-value }\end{array}$ & $\begin{array}{l}-0.01 \\
0.94\end{array}$ & $\begin{array}{l}0.22 \\
0.18\end{array}$ & $\begin{array}{l}-0.11 \\
0.50\end{array}$ & $\begin{array}{l}-0.04 \\
0.78\end{array}$ & $\begin{array}{l}-0.30 \\
0.07\end{array}$ & $\begin{array}{l}-0.16 \\
0.34\end{array}$ & $\begin{array}{c}-0.22 \\
0.18\end{array}$ & $\begin{array}{l}-0.07 \\
0.66\end{array}$ \\
\hline $\begin{array}{l}\text { Pre-failure } \\
\text { kidney dis. } \\
\text { P } \\
\text { p-value }\end{array}$ & $\begin{array}{r}-0.14 \\
0.41\end{array}$ & $\begin{array}{l}0.35^{*} \\
0.03\end{array}$ & $\begin{array}{l}0.05 \\
0.74\end{array}$ & $\begin{array}{l}-0.05 \\
0.74\end{array}$ & $\begin{array}{l}0.15 \\
0.38\end{array}$ & $\begin{array}{l}-0.13 \\
0.43\end{array}$ & $\begin{array}{l}0.09 \\
0.60\end{array}$ & $\begin{array}{l}-0.15 \\
0.37\end{array}$ \\
\hline $\begin{array}{c}\text { Previous CVC + } \\
\text { BSI history } \\
\rho \\
\text { p-value }\end{array}$ & $\begin{array}{l}0.26 \\
0.12 \\
\end{array}$ & $\begin{array}{l}-0.12 \\
0.46 \\
\end{array}$ & $\begin{array}{l}0.34^{*} \\
0.04\end{array}$ & $\begin{array}{l}0.25 \\
0.13 \\
\end{array}$ & $\begin{array}{l}0.02 \\
0.91 \\
\end{array}$ & $\begin{array}{l}-0.15 \\
0.38 \\
\end{array}$ & $\begin{array}{c}-0.04 \\
0.79 \\
\end{array}$ & $\begin{array}{l}0.29 \\
0.08 \\
\end{array}$ \\
\hline $\begin{array}{c}\text { Insertion date } \\
\rho \\
\text { p-value }\end{array}$ & $\begin{array}{l}0.12 \\
0.48\end{array}$ & $\begin{array}{l}-0.48^{*} \\
0.003\end{array}$ & $\begin{array}{l}0.10 \\
0.53\end{array}$ & $\begin{array}{l}0.10 \\
0.55 \\
\end{array}$ & $\begin{array}{l}-0.19 \\
0.26 \\
\end{array}$ & $\begin{array}{l}-0.20 \\
0.23 \\
\end{array}$ & $\begin{array}{l}0.05 \\
0.74 \\
\end{array}$ & $\begin{array}{l}0.061 \\
0.728 \\
\end{array}$ \\
\hline $\begin{array}{l}\text { Inserted by } \\
\rho \\
p \text {-value }\end{array}$ & $\begin{array}{c}0.006 \\
0.97\end{array}$ & $\begin{array}{l}0.36^{*} \\
0.03\end{array}$ & $\begin{array}{l}-0.02 \\
0.87\end{array}$ & $\begin{array}{l}0.32 \\
0.05\end{array}$ & $\begin{array}{l}0.18 \\
0.28 \\
\end{array}$ & $\begin{array}{l}-0.49^{*} \\
0.003\end{array}$ & $\begin{array}{l}-0.59^{*} \\
<0.0001\end{array}$ & $\begin{array}{l}-0.322 \\
0.059 \\
\end{array}$ \\
\hline $\begin{array}{l}\text { Vein used } \\
\rho \\
p \text {-value }\end{array}$ & & $\begin{array}{r}-0.06 \\
0.70\end{array}$ & $\begin{array}{l}0.18 \\
0.29\end{array}$ & $\begin{array}{l}0.13 \\
0.44\end{array}$ & $\begin{array}{l}0.13 \\
0.42\end{array}$ & $\begin{array}{l}-0.11 \\
0.51\end{array}$ & $\begin{array}{l}0.19 \\
0.26\end{array}$ & $\begin{array}{l}0.35^{*} \\
0.03\end{array}$ \\
\hline $\begin{array}{l}\text { \# catheter/day } \\
\rho \\
\text { p-value }\end{array}$ & $\begin{array}{c}-0.24 \\
0.15\end{array}$ & $\begin{array}{l}0.55^{*} \\
0.001\end{array}$ & $\begin{array}{l}0.11 \\
0.49\end{array}$ & $\begin{array}{l}0.44^{*} \\
0.007\end{array}$ & $\begin{array}{l}0.37^{*} \\
0.02\end{array}$ & $\begin{array}{l}-0.48^{*} \\
0.003\end{array}$ & $\begin{array}{c}-0.61^{*} \\
<0.0001\end{array}$ & $\begin{array}{l}-0.16 \\
0.34 \\
\end{array}$ \\
\hline $\begin{array}{l}\text { Complete } 1 \mathrm{yr} \\
\rho \\
\mathrm{p} \text {-value }\end{array}$ & $\begin{array}{c}-0.06 \\
0.70 \\
\end{array}$ & & $\begin{array}{l}-0.19 \\
0.27 \\
\end{array}$ & $\begin{array}{l}0.25 \\
0.13 \\
\end{array}$ & $\begin{array}{l}0.02 \\
0.91 \\
\end{array}$ & $\begin{array}{l}-0.43^{*} \\
0.008\end{array}$ & $\begin{array}{c}-0.26 \\
0.11 \\
\end{array}$ & $\begin{array}{c}-0.08 \\
0.61 \\
\end{array}$ \\
\hline $\begin{array}{l}\text { Complete } 6 \text { mos } \\
\rho \\
p \text {-value }\end{array}$ & $\begin{array}{l}0.18 \\
0.29\end{array}$ & $\begin{array}{l}-0.19 \\
0.27 \\
\end{array}$ & & $\begin{array}{l}0.32 \\
0.05\end{array}$ & $\begin{array}{l}0.48^{*} \\
0.003\end{array}$ & $\begin{array}{l}-0.17 \\
0.32 \\
\end{array}$ & $\begin{array}{c}<0.0001 \\
1.000\end{array}$ & $\begin{array}{l}0.23 \\
0.16 \\
\end{array}$ \\
\hline $\begin{array}{l}1^{\text {ry }} \text { device ser- } \\
\text { vice interval } \\
\rho \\
\text { p-value }\end{array}$ & $\begin{array}{l}-0.26 \\
0.26 \\
\end{array}$ & & $\begin{array}{l}0.24 \\
0.30 \\
\end{array}$ & $\begin{array}{l}0.47^{*} \\
0.03\end{array}$ & $\begin{array}{l}0.48^{*} \\
0.03\end{array}$ & $\begin{array}{c}-0.23 \\
0.31 \\
\end{array}$ & $\begin{array}{l}-0.59^{*} \\
0.005\end{array}$ & $\begin{array}{l}-0.13 \\
0.58 \\
\end{array}$ \\
\hline $\begin{array}{l}\text { Reported } \\
\text { events of BSI } \\
\rho \\
\text { p-value }\end{array}$ & $\begin{array}{l}0.13 \\
0.44 \\
\end{array}$ & $\begin{array}{l}0.25 \\
0.13 \\
\end{array}$ & $\begin{array}{l}0.32 \\
0.05 \\
\end{array}$ & & $\begin{array}{l}0.47^{*} \\
0.004\end{array}$ & $\begin{array}{c}-0.68^{*} \\
<0.0001\end{array}$ & $\begin{array}{l}-0.46^{*} \\
0.005\end{array}$ & $\begin{array}{l}0.05 \\
0.77 \\
\end{array}$ \\
\hline $\begin{array}{l}\text { Infection Onset } \\
\rho \\
p \text {-value }\end{array}$ & $\begin{array}{l}0.13 \\
0.42 \\
\end{array}$ & $\begin{array}{l}0.02 \\
0.91 \\
\end{array}$ & $\begin{array}{l}0.48^{*} \\
0.003\end{array}$ & $\begin{array}{l}0.47^{*} \\
0.004\end{array}$ & & $\begin{array}{l}-0.16 \\
0.34 \\
\end{array}$ & $\begin{array}{l}-0.13 \\
0.42 \\
\end{array}$ & $\begin{array}{l}0.14 \\
0.41 \\
\end{array}$ \\
\hline $\begin{array}{l}\text { Fate } \\
\rho \\
\text { p-value }\end{array}$ & $\begin{array}{l}-0.11 \\
0.51\end{array}$ & $\begin{array}{l}-0.43^{*} \\
0.008\end{array}$ & $\begin{array}{l}-0.17 \\
0.32 \\
\end{array}$ & $\begin{array}{c}-0.68^{*} \\
<0.0001\end{array}$ & $\begin{array}{r}-0.16 \\
0.34 \\
\end{array}$ & & $\begin{array}{c}0.62^{*} \\
<0.0001 \\
\end{array}$ & $\begin{array}{l}-0.03 \\
0.82 \\
\end{array}$ \\
\hline
\end{tabular}


Number of catheter days and fate of catheter/patient. Catheter completion of 1 year in-site and fate of catheter/patient. Primary device service interval and reason for catheter-removal. Reported events of catheter-related blood stream infection and reason of catheter-removal. Fate of catheter/patient and catheter-inserting person. Fate of catheter/patient and catheter completion of 1 year in-site. while, a significant strong negative correlation between: Number of catheter days and reason for catheter removal. Reported events of catheter-related blood stream infection and fate of catheter/patient. Fate of catheter/patient and reported events of catheter-related blood stream infection, (table 8).

\section{Discussion}

In this prospective study, we report the outcome of a 35-placed tunneled cuffed catheters. Total of 528 patient-months 6343 catheter days a reasonable period related to the number of placed catheter from which we can illustrate the fate of TCCs at our facility. 14 catheters (40\%) were removed due to either non-function or possible catheter related infection. The reason for removal with the higher incidence was malfunction. We found in patients in whom there was a history of previously inserted catheter and removed a reduced primary device service interval, a previous study done by $M A$ little et al (10) found a similar result and suggested that this due to that the host vein structure get altered primarily due to wall injury by the indwelling catheter this effect is augmented if an episode of thrombosis or CRS was superimposed on it. In 6 cases (42.85\% of the removed catheters) the TCC was removed and replaced in the same setting revealing the degree of need for these devices that has been established and their importance in long term hemodialysis. Of the patients followed 4 catheters (11.4\%) were still functioning at 1 year, and the half-life survival was 6 months. We found that the most powerful predictor of 6 months' survival was the previous history of blood stream infection associated with a previously placed catheter weather temporary or permanent catheter $(p=0.04)$ when this history is present the probability of the catheter get infected before reaching 6 months' life time is increased despite changing access site. In our study patient mean age $59.17 \pm 12.5$ and 11 (31.4\%) of patients $\geq 65$ years these figures are close to the patient population of canaud et al $^{(11)}$ they reported median survival as 2.5 years with incidence of failure of $7.6 \%$ at 4 years and concluded that $\mathrm{HC}$ is an excellent vascular access in elderly however this study excluded $\mathrm{HC}$ functioned $<90$ days and the ones inserted in the SCV in our study we included them which is the same done by Little et $\mathrm{al}^{(10)}$, and found a too much shorter HC survival T half of 6 months and a much higher incidence of failure $20 \%$ and sepsis $54.2 \%$. Moss et al in $1990^{(12)}$ formed study similar to this and found 1 year survival of $65 \%$ and median survival was 18.5 months compared to respective figures $11.4 \%$ and 6 months in our study a more recent study performed by $M$ A little et $\mathrm{al}^{(10)}$ found respective results of $47.5 \%$ and 10 months it is obvious that our results of survival are low compared to the mentioned studies. We suggest that it is due to the broken cycle of patient close follow up also the delayed intervention given to the patient in response to the timing of emergence of the catheter related complication. A striking contrast the percentage of catheters removed due to malfunction and sepsis according to moss 
et al was $15 \%$ while according to $M A$ little et al $^{(10)}$ was $52 \%$ and according to our study was $37 \%$ this result does seem better but in reality it is not the reason why not all patients experiencing episodes of CRS have removed their catheters the truth is they survived these episodes using antibiotics the patients survived on antibiotics numbered 14 (40\%) they all refused catheter removal for fear of losing their only dialysis access as most of them had experienced failed access trials before. The frequency of $\mathrm{HC}$ related sepsis in our study was 2.186 per 1000 catheter days. According to moss et $\mathrm{al}^{(12)}$ was 0.69 per 1000 catheter days, another study done by Marr et al ${ }^{(7)}$ found a frequency of $\mathrm{HC}$ related sepsis of 3.9 per 1000 catheter days, while according to Beathard's study (13) was 3.4 per 1000 catheter days, and $M$. A. Little et al ${ }^{(10)}$ was 1.3 per 1000 catheter days. Of the infected catheters total number $19(54.28 \%)$ the onset of reported infection was $2(5.7 \%)$ in the first week , 1 (2.9\%) in the first month, and 16 (45.7\%) after the first month according to this We can link the incidence of catheter related sepsis onset to the place of origin weather the placement hospital or the dialysis facility we believe from the results and the course of catheter till its removal that the infection begins in the dialysis facility most probably due to under trained nurses who cannot execute infection control and hub care protocols. In our study the incidence of CRS we have concluded is partly due to event description history of episode of fever, hypotension and rigors persistent not relieved except after catheter removal and other patients who have performed blood culture. Of all the performed cultures the reported organism was pseudomonas aerogenosa which is a gram negative organism beathhard's study (13) reported gram negative organism incidence of $33.3 \%$ which is very high compared to little et al $^{(10)}$ which is less than $2 \%$ the drawbacks in here are first that not all the patients of fever and malaise are cultured in our facility protocols and second there is no evidence to tell that this gram negative infection are all CRBSI again due to broken cycle of follow up. The patients whom blood culture revealed gram negative organism were experiencing events of intermittent rigors most probable timing of occurrence was during dialysis session these events were partially controlled using antibiotics first vancomycin then piperacillin/tazobactam or carbapenem antibiotics according to sensitivity 5 (26.3\% of the supposed infected catheters) catheters were removed due to severe event of fever, rigors, and hypotension not controlled by medications $3(15.78 \%$ of the supposed infected catheters) of them got better dramatically after removal and were put on temporary access then switched on surgically performed vascular access and 2 (10.5\% of the supposed infected catheters) of them died during the circumstances of the event so it is suggested that there death was due to CRBSI.

\section{Conclusion}

Previous history of blood stream infection associated with a dialysis catheter increases the probability of infection to the newly inserted permanent catheter, before reaching 6 months' life time despite changing access site.

\section{References}

1. NKF-DOQI, "clinical practice guidelines and recommendations for 2006 update: Hemodialysis Adequacy, Peritoneal Dialysis Adequacy and Vascular Access. AJKD, 2006: 48: S1-S322, 2006 (suppl 1).

2. Saxena AK and Panborta BR, "Hemodialysis catheter-related bloodstream infections: current treatment options and strategies for prevention, "Swiss 
Medical Weekly, 2005, 135 (9-10),. 127138.

3. Burr R, Marszalek J, Saul M, Shields M, Aslam N. The Cost of Vascular Access Infections: Three Years' Experience from a Single Outpatient Dialysis Center. Hemodialysis International, 2003; 7(1): 73-104.

4. Maki DG, Kluger DM, Crnich CJ. The Risk of Bloodstream Infection in Adults with Different Intravascular Devices: A Systematic Review of 200 Published Prospective Studies. Mayo Clin Proc. 2006 ;81(9):1159-71

5. C. Ronco and N. W. Levin, Eds., in Hemodialysis Vascular Access and Peritoneal dialysis Access, vol. 142, Basel, Karger, 2004, 112-27.

6. Rackoff WR, Weiman M, Jakobowski $\mathrm{D}$, et al. A randomized, controlled trial of the efficacy of a heparin and vancomycin solution in preventing central venous catheter infections in children. J ped, 1995; 127 (1):147-51.

7. Marr KA, Sexton DJ, Conlon PJ, Corey $G R$, Schwab SJ and Kirkland KB, "Catheter-related bacteremia and outcome of attempted catheter salvage in patients undergoing HD," Annals Int Med, 1997; 127 (4), 275-80.

8. Rotellar C, Sims SC, Freeland J, Korba J, Jessen M, Taylor A. Right Atrium Thrombosis in Patients on hemodialysis. Am J Kidney Dis. 1996; 27(5):726-8.

9. Schwab SJ, Beathard G.The hemodialysis catheter conundrum: Hate living with them, but can't live without them. Kidney Int. 1999;56(1):1-17.

10. Little MA, O'Riordan A, Lucey B, et al. A prospective study of complications associated with cuffed, tunnelled haemodialysis catheters," Nephrology Dialysis Transplantation, 2001; 16: 2194-200.

11. Canaud B, Leray-Moragues H, Garrigues $\mathrm{V}$, and Mion $\mathrm{C}$, "Permanent twin catheter: A vascular access option of choice for hemodialysis in elderly patients," Nephrology Dialysis Transplantation. 1998; 13 (7), 82-8.
12. Moss AH, Vasilakis C, Holley JL, Foulks CJ, Pillai K, McDowell DE. Use of a Silicone Dual-Lumen Catheter with a Dacron Cuff as a Long-Term Vascular Access for Hemodialysis Patients. Am J Kidney Dis. 1990;16(3):211-5.

13. Beathard GA. Management of Bacteremia Associated with TunneledCuffed Hemodialysis Catheters. J Am Soc Nephrol, 1999 ;10(5):1045-9. 
